\title{
Focus on the Development of Energy Internet in China
}

\author{
Ren Lingzhi ${ }^{1^{*}}$, Wang Ling ${ }^{2}$, Zhao Xin-gang ${ }^{1}$
}

School of Economics and Management, North China Electric Power University, Beijing, 102206, China

State Grid Liaoning Electric power co., LTD. Benxi Power Supply Company, Benxi, 117000, China

Keyword: Energy Internet; Renewable energy; Energy power system.

\begin{abstract}
In order to promote the large-scale use of distributed renewable energy and improve energy efficiency, many countries started to pay close attention to the development of energy Internet. Europe, the United States, Japan and other developed countries has made some breakthrough in the field of energy Internet construction. The paper mainly analyzed and summarized the development of energy Internet. Some successful projects of energy Internet in the developed countries are introduced. And then the paper summarized the status quo and development plan of China's energy Internet. Finally, gave some conclusions for the paper. We held that China draw experience from the development of energy Internet in developed countries and find the development road for the construction of energy Internet according to practice of the nation
\end{abstract}

\section{INSTRUCTION}

With the development of energy technology and Internet technology, energy Internet gradually became the new development and research direction in the field of energy, and attracted the attention of many countries in the world. Energy Internet is a kind of new and high-efficiency power network structure, it can use advanced Internet technology to syncretize large numbers of distributed renewable energy power generation devices and distributed energy storage devices on basis of the existing distribution network, and then realize the two-way flow between energy and information [YU Shenhang, 2010]. The core purpose of energy Internet development is to use the Internet technology to promote information interaction among all kinds of equipment in the big energy networks, and then realize the real-time balancing between energy production and energy consumption. In the future, the energy Internet will develop into the super large IOT that consists of tens of billions of power components and electrical components. Then it will become the biggest network in the human subsystems, and each electric-equipment may be a node and unit of energy Internet.

The energy Internet is a new way of energy supply on basis of urban compact and densely populated community in low-carbon city and it will play an increasingly important role in our life [Liang Hao, 2011]. The energy Internet can achieve the flexible energy and power dispatch by allowing customers to compete with each other and maximize their own benefits [Wencong Su, 2013]. Compared with the traditional energy supply system, the energy Internet can make full use of the technology advantages of energy comprehensive utilization to optimize the supply and consumption of energy, and improve the overall utilization efficiency of energy [Zhou Hai-ming, 2014]. Besides, many scholars researched on the energy Internet from different perspectives, such as renewable energy delivery and management [Huang, A.Q., 2010], energy router technology and its functions [CAO JunWei, 2014] [Yi Xu, 2011] and the comparison between energy Internet and the smart grid [Dong Zhaoyang, 2014] [Tsoukalas L.H., 2008]. Based on the existing research, the paper studied and summarized the development of domestic and international energy Internet, and provided some suggestions for the development of China's energy Internet. 


\section{THE DEVELOPMENT OF INTERNATIONAL ENERGY INTERNET}

The original purpose of global energy Internet is to adapt the global clean energy development, transmission and market consumption. By 2050, the global clean energy power generation will reach 12 trillion $\mathrm{kWh}$, and the dominant force of international energy system will gradually turn to the energy Internet direction in the rapid development of clean energy. At present, the energy Internet has become the new growth point of the global economy, the Europe, America and Japan are vigorously developing the energy Internet related projects.

There are three kinds of points on the connotation of energy Internet, based on the energy Internet development of developed countries. Firstly, it is called the Internet of energy. The Internet of energy uses the Internet to collect information on energy, and then guide the running \& scheduling of the energy grid on the basis of analysis and decision. The nature of the Internet of energy is still information Internet, and the typical representative is European E-Energy. Secondly, it is called energy Internet. The energy Internet adopts the open peer theory and system structure of the Internet to construct a new energy grid. The nature of energy Internet is a distributed energy network, and it is typically represented by American FREEDM project. Thirdly, it is called intenergy, namely innovative energy internet. The intenergy is the depth of integration between the Internet technology and energy network, and it is difficult to distinguish the energy network and information network from the structure of intenergy. The typical representative is the digital power grid and power router of Japan.

\subsection{The Internet of energy in Germany}

As the world's fourth-largest economy, Germany has been at the forefront of energy conservation and emission reduction, and obtained remarkable accomplishment in the exploration of new energy system. The renewable energy in Germany accounted for 25 of total electricity production in 2014, and was expected to rise to 35 percent by 2020. Germany hoped to rely on technical innovation to meet the needs of distributed energy. Back in 2008, Germany's technical economy department and the ministry of environment introduced E-Energy planning and put forward the target of the construction of new type energy network, namely energy Internet. In order to cope with the influence of distributed energy development on power system and maximize the use of wind power and photovoltaic, E-Energy makes full use of information and communication technology to develop new solutions, realizes comprehensive digital connections and computer control and monitoring in the whole energy supply system, and finally achieves the state that power production decides electricity consumption. At present, Germany is creating a new energy system that is likely to lead the world trend.

E-Energy can realize the intercommunication and coordination between power grid infrastructures and electrical appliances. When wind power and photovoltaic is enough, power price will be reduced due to the electricity surplus. The consumers can timely open electrical appliances, such as refrigerators, washing machines, dishwashers. Besides, the car owners can charge the cars' battery at lower cost or only use "green power" to charge the battery in this time period. When enter the electrical peak load, E-Energy systems can obtain surplus electricity from batteries, and feed it back to the power grid. A new electronic Energy market will be formed in the E-Energy system, and the customers are both power consumers and power consumers in the market. As small power suppliers (such as through solar panels), the consumers are able to play more active role in the energy Internet.

E-Energy plan is currently being undertaken in Germany's six areas, and the test subjects of energy Internet are different in different regions [Wang Xiwen, 2011]. Take the RegMod project of Harz as an example, RegMod project is a comprehensive energy Internet project, and its core demonstration content is to integrate the virtual power plants of energy storage facilities, electric vehicles, renewable energy and intelligent home appliances. When there is a glut of renewable en- 
ergy power generation, pumped storage power station and electric cars can store excess green electricity. Besides, intelligent household appliances, such as intelligent washing machines, smart dishwasher and intelligent water heater etc., will be timely opened to consume the extra green power. When the power demand is climbing, these virtual power plants, which are composed by storage facilities and intelligent electrical appliances, can relieve tense electricity consumption demand by releasing the stored electricity and reducing the electricity consumption of intelligent electrical apparatus. RegMod project contains a lot of the energy Internet elements, including electric cars, distributed renewable energy, smart appliances, storage facilities, etc., and it is the prototype of the energy Internet.

\subsection{The Energy Internet in America}

The FREEDM plan of American energy Internet is to establish the revolutionary power grid structure that has functions of wisdom, and absorb a large number of distributed energy, under the support of power electronics, high-speed digital communication and distributed control technology. The target of FREEDM is to achieve the efficient utilization and compatibility of renewable energy by the comprehensive control of the production, transmission and consumption of energy.

The United States took the smart grid construction as the locomotive to promote energy Internet development. The smart grid technology is mainly used in the smart grid platform, power grid monitoring and management, smart metering, demand management, integration of renewable energy, plug-in petrol-electric hybrid or pure electric vehicles, etc. As early as in August 2008, the first phase of the smart grid project was completed in Boulder Colorado, and the Boulder became the first smart grid city in America. The smart meters installed in customers' homes can realize twoway communication with electric power company, and the consumers are able to know the realtime electricity price. Then consumers can avoid the peak stage of power load, and also give priority to the use of clean energy, such as wind power and solar energy. All users' electricity data and status can be collected by intelligent substations, and once appear problem, the electricity can be redistributed immediately.

\subsection{The Energy Internet in America}

Unlike the energy Internet of United States, the digital power grid in Japan built on top of information on the Internet, and the Internet technology provides information support for the digital power grid. Japan breaks synchronous grid into asynchronous autonomous and interconnected sub power grid gradually, and then assigns IP addresses for generators, power converters, wind farms, storage system, roof solar cells and other grid infrastructures [Deng Xuemei, 2013]. The key technology of digital power grid is the power router. The power routers are connected to the existing power grid and energy local area network, and it can identify power supplies and energy bases according to the "IP address". The digital power grid in Japan aims to complete energy distribution via the power routers.

Besides, considering the regional differences existed in the present situation of the current frequency, VPEC Company developed a technology, which can find the information contained in electric current, and designed the digital power supply system "ECO network" that need not rely on the support of specialized information network. The power routers can estimate the remaining electric energy of nearby storage battery according to the frequency information of the neighboring power router, and then alter the frequency of the output power. The information of "ECO network" comes from the electricity characteristic, this reduce the dependence on information infrastructure. The structure of digital power grid is relatively simple, and it can provide the reference for the construction of lightweight energy Internet.

\section{THE DEVELOPMENT OF CHINA'S ENERGY INTERNET}


Chinese Prime Minister Li Keqiang pointed out the "Internet +" action plan in the CPPCC reports of 2015. The "Internet +" was formally incorporated into the top-level design, and become the important strategy of national economic and social development. In fact, the "Internet + energy" in China had begun trial in early2015. On February 10, 2015, the national wisdom energy cloud platform of public service, which was initiated by wisdom energy industry technology innovation strategic alliance, was officially launched. The cloud platform was mainly applied in the construction and management of energy great data. China can use the cloud platform to collect and integrate the national energy data, organize the public resources, and provide the real-time monitoring, data storage, visualization, data analysis, risk control, energy efficiency management and other services. Besides, the platform of public service mainly relied on the international standards of energy Internet (ISO/IEC/IEEE18880) to build the energy management mode based on the Internet infrastructure.

In April 2015, the national energy administration convened the first Internet work session, and planned to formulate the action plan of national energy Internet based on the top-level design. It indicated that China officially started to build the energy Internet. The original purpose of energy Internet in China is to cope with the development bottlenecks of energy resources, especially renewable energy. In the middle of April 2015, several energy research institutions jointly issued "research on the situation and path of China 2050 high proportion renewable energy development". The report predicted that by 2050, the direct consumption fossil fuels would reach 900 million tons standard coal, and the proportion of non-fossil energy in China's terminal energy consumption would reach $66 \%$; in the terminal power supply, the proportion of non-fossil energy electricity and renewable energy would reach 91\% and 62\% respectively. Besides, energy efficiency would increase $90 \%$ compared with 2010, and energy consumption per unit of GDP would be 0.12 tons of standard coal per ten thousand Yuan. It indicated that the trend of China's energy transformation was irreversible. The German energy transformation proved that the Internet of energy was a viable choice for energy transformation.

China has formulated the development roadmap of energy Internet (See Fig.). The fig. showed that the development of energy Internet in China was divided into four phases, namely the first phase (2015-2020), the second phase (2017-2023), the third phase (2020-2025) and the fourth phase (2025-2030). In the first stage, the main task is to build energy Internet infrastructure, including the popularization of distributed energy, energy storages, smart meters, charging piles and intelligent inverters. The second phase is to establish the electric power market mechanism, and encourage the subjects of different industries to enter power sale field. And then, due to the volatility of power generation subjects, China will gradually open up electricity distribution market and promote the intelligent of the power distribution in the third phase. In the fourth stage, Intermediate energy Internet construction will be completed basically, and the electricity distribution will achieve intelligence, and even has the ability of independent evolution and self-healing.

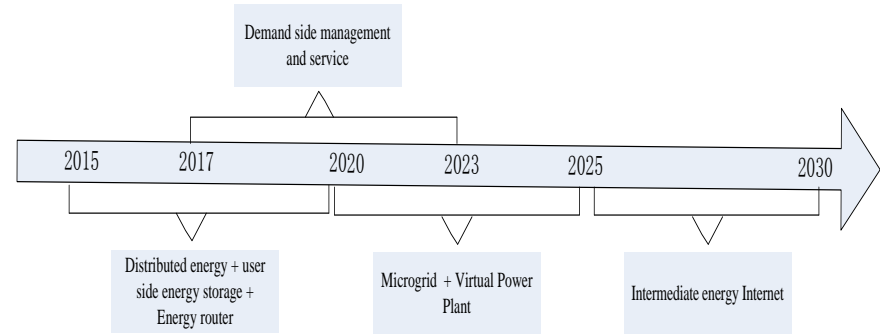

Figure. The development roadmap of energy Internet in China.

\section{CONCLUSION}

At present, the energy power system faces a series of challenges. Firstly, the rapid development of renewable energy causes huge impact on traditional energy system, especially the power grid system. Secondly, power \& energy industries are faced with the problems of assets loss and huge maintenance. Thirdly, the consumers' demand for the services and information of energy power is 
increasing, but the current situation of energy power system cannot meet the demand. Fourthly, energy power system itself is faced with the deployment contradiction of the electricity peak valley. The development of energy Internet provides a new turnaround to alleviate the challenges of China's energy power system. The energy Internet will cause certain impact to the existing energy systems, and the system, rules, and ecology of energy power industry will be rebuild with the development of energy Internet.

China's position in the international energy system will depend on the independent innovation of energy Internet construction. China can draw lessons from the attempt and exploration of energy Internet in German, United States and Japan, and find a development road of energy Internet, which conform to the situation of china. Besides, China should coordinate domestic resources and implement the financing credit policy, technology transfer policy and restructuring policy, in order to realize the leap-forward development of China's energy Internet in the shortest possible time.

\section{ACKNOWLEDGEMENT}

This article is supported by "Science and technology project funding by State Grid Liaoning electric power co., LTD. Benxi Power Supply Company” (Grant No. FZJS1400820 and FZJS1400823).

\section{REFERENCES}

[1] YU Shenhang et al. 2010. Energy Internet system based on distributed renewable energy generation. Electric Power Automation Equipment 5(30): 104-108.

[2] Liang Hao. 2011. Future Energy System in Low-Carbon Community-Energy Internet. Computer Distributed Control and Intelligent Environmental Monitoring (CDCIEM), 2011 International Conference on pp. $227-230$.

[3] Wencong Su et al. 2013. Proposing an electricity market framework for the Energy Internet. IEEE Power and Energy Society General Meeting (PES) pp.1-5.

[4] Zhou Hai-ming et al. 2014. Study on the Energy Internet Technology Framework. Electric Power 11(47): 140-144.

[5] Huang, A.Q. et al. 2010. The Future Renewable Electric Energy Delivery and Management (FREEDM) System: The Energy Internet. Proceedings of the IEEE 1(99): 133 - 148.

[6] CAO JunWei et al. 2014. An energy internet and energy routers. China science, information science 6(44):714-727.

[7] Yi Xu et al. 2011. Energy router: Architectures and functionalities toward Energy Internet. Smart Grid Communications (SmartGridComm), 2011 IEEE International Conference on pp. $31-36$.

[8] Dong Zhaoyang et al. 2014. From smart grids to an energy internet: Basic Concept and Research Framework. Automation of Electric Power System 15(38):1-11.

[9] Tsoukalas L.H. et al. 2008. From smart grids to an energy internet: Assumptions, architectures and requirements. Electric Utility Deregulation and Restructuring and Power Technologies, 2008Third International Conference on pp. $94-98$.

[10]Wang Xiewen et al. 2011. The promoting plan of German informatization energy (E-Energy). Power Demand Side Management 4(13): 75-76+80.

[11]Deng Xuemei. 2013. Digital Power Grid Plan in Japan. World Science 07:19+9. 